\title{
Endoscopic variceal ligation for treatment of bleeding varices
}

JOHN S GOFF, MD

JS GOFF. Endoscopic variceal ligation for treatment of bleeding varices. Can J Gastroenterol 1992;6(4):213-217. Endoscopic variceal ligation (EVL) was developed as an alternative to endoscopic variceal sclerosis (ES) because of the latter's high complication rate. The new technique involves placement of small elastic bands around the variceal channels in the distal esophagus. Initial open trials with EVL showed that it was safe and effective therapy for bleeding esophageal varices. EVL can be used emergently to control actively hemorrhaging varices and electively to eradicate varices with repeated sessions. When compared directly with results obtained with ES retrospectively and prospectively), EVL is equal or superior in preventing rebleeding while causing many fewer complications. Combining the two techniques may be even more effective than either alone at eradicating varices. Combination therapy has achieved eradication of varices in an average of three sessions, which is one to three fewer sessions than generally reported to achieve eradication with EVL or ES alone. Combination therapy has also been used to control bleeding gastric varices effectively. EVL, alone or with low dose ES, seems to be the safest and most effective endoscopic means for controlling bleeding from esophageal or gastric varices. EVL needs to be evaluated for prophylactic treatment of esophageal varices since its low morbidity profile may make it more suitable than ES for prophylactic treatment.

Key Words: Sclerotherapy, Variceal bleeding, Variceal ligation endoscopy

\section{Traitement de varices hémorragiques au moyen de la ligature par voie endoscopique}

RÉSUMÉ: Une technique de ligature de varices par voie endoscopique a été mise au point comme solution de rechange au traitement sclérosant des varices par voie endoscopique à cause du taux élevé de complications associées à cette dernière. La nouvelle technique repose sur l'installation de petites bandes élastiques autour des canaux variqueux au niveau de l'oesophage distal. Les essais

University of Colorado Health Sciences Center and Denver Veterans Administration Medical Center, Denver, Colorado, USA

Correspondence and reprints: Dr JS Goff, 209 North Overland Trail, Fort Collins, CO 80521, USA
E NDOSCOPIC SCLEROTHERAPY (ES) widely is used to treat bleeding esophageal varices. Despite widely varying techniques for ES, complications occur frequently - deep esophageal ulceration with and without perforation is the most dangerous. Ulcerations occur in 40 to $80 \%$ of patients and perforation rates are reported from 1 to $6 \%(1,2)$. Deep ulcers also contribute to the relatively high rate of stricture formation after ES (3 to 20\%) $(3,4)$.

The technique of endoscopic variceal ligation (EVL) was developed to achieve efficacy similar to, or better than, ES with fewer complications $(5,6)$. EVL is similar to hemorrhoidal banding in which small elastic o-rings are endoscopically placed around a piece of mucosa containing dilated vessels. During the past four years, this technique has been developed, tested and modified at the author's two teaching hospitals and at several other centres around the world. Complications, rebleeding, survival and ability to eradicate varices from the distal esophagus and stomach have been studied in patients who have bled from esophageal or gastric varices. EVL has been studied alone, in combination with ES and in direct comparison to ES (6-10). 
clinques ouverts initiaux sur la ligature des varices par voie endoscopique l'ont révélée sûre et efficace pour le traitement des varices oesophagiennes qui saignent. La ligature des varices par voie endoscopique peut être utilisée en cas d'urgence pour maîtriser efficacement les varices qui saignent et en traitement électif pour éliminer les varices par étapes. En comparaison directe avec les résultats obtenus avec la technique sclérosante (rétrospectivement et prospectivement), la ligature est égale ou supérieure pour la prévention de la récurrence du saignement et donne lieu à moins de complications. Une combinaison des deux techniques pourrait se révéler encore plus efficace que le recours à l'une ou l'autre seule. Le traitement d'association a donné lieu à une élimination des varices en trois séances en moyenne, ce qui représente d'une à trois séances de moins qu'il n'en faut généralement pour parvenir à éliminer la problème avec la ligature ou la technique sclérosante seule. Le traitement d'association a également été utilisé pour maitriser efficacement le saignement de varices gastriques. La ligature seule ou en association avec la technique sclérosante semble être la plus sûre et la plus efficace des méthodes endoscopiques pour maîtriser le saignement de varices oesophagiennes ou gastriques. Il reste à déterminer le rôle de la ligature dans le traitement prophylactique des varices oesophagiennes, puisque son faible taux de morbidité est appelé à lui donner un rôle de choix dans ce domaine.

\section{PATIENTS AND METHODS}

EVL technique: The technique for EVL has been previously described $(6,8)$. Patients are sedated and endoscoped using a variety of standard and therapeutic endoscopes. The endoscope is prefitted with a $25 \mathrm{~cm}$ semiflexible overtube that is introduced over the endoscope into the oropharynx and upper esophagus after the endoscope has been passed in the usual manner and the upper gastrointestinal tract has been thoroughly examined. The overtube allows one to remove readily the endoscope for loading and unloading the ligation device. The ligating device (Bard International Inc, Massachusetts) consists of an outer cylinder attached to the tip of the endoscope, an inner cylinder around which the elastic o-ring (rubber band) is attached and a trip wire that is passed down the biopsy channel of the endoscope and hooked to the inner cylinder (Figure 1). The outer cylinder creates some dead space at the tip of the endoscope to allow tissue containing a varix to be aspirated into it. Once the tissue is fully within the dead space at the tip of the endoscope, the trip wire is pulled, forcing the inner cylinder further into the outer cylinder which causes the rubber band to be stripped off. The band then closes around the tissue, strangulating the varix. The endoscope is removed and a fresh inner cylinder is loaded onto the endoscope. The ligating process is repeated until all the major variceal channels are ligated once or twice (four to 12 bands). At subsequent sessions, which occur at seven days and then every two weeks until the varices are eradicated, usually one band is applied per variceal column unless a column remains very large (in which case more may be applied). The ligations are started at the gastroesophageal junction and are subsequently applied in an upward spiraling manner. The goal is to eradicate all variceal channels in the distal $5 \mathrm{~cm}$ of the esophagus. After treatment, the patients are started on a liquid diet and advanced as tolerated over $24 \mathrm{~h}$. If significant ulceration develops in the esophagus, patients are started on either sucralfate slurries four times a day or an $\mathrm{H}_{2}$ antagonist twice a day. Once the varices appear to be eradicated by gross inspection, the interval between follow-up endoscopies starts to increase. The first visit after eradication is at one month with subsequent visits at threeto six-month intervals unless recurrent varices requiring more than a single treatment session for eradication are seen.

Combination technique: EVL was combined with ES to determine whether quicker eradication of varices could be achieved (7). The advantages of quicker eradication would be fewer treatment sessions and less rebleeding (the majority of rebleeding episodes occur during the interval from the start of therapy until variceal eradication is achieved). During combination therapy, patients are intubated with the endoscope and overtube in the usual fashion. After examination, four to six ligations are performed at or near the gastroesophageal junction. Each varix is ligated once; large ones may be ligated at two levels. The ligating device is removed from the tip of the endoscope and a 23 gauge sclerotherapy needle is passed down the biopsy channel. Each visible varix is injected with $1 \mathrm{~mL}$ of $1 \%$ sodium tetradecyl sulphate just above the level of the ligations (Fig. ure 2 ). The process is repeated in one week and then every two weeks until the varices are eradicated. When the veins become very small, only ES is performed as needed. Long term follow. up is the same as with EVL.

Patient selection: Patients entering the various trials were quite diverse; all had to have verified variceal hemorrhage either by confirmed actively bleeding varices or major upper gastrointestinal bleeding with no other reasonable source seen at endoscopy. Many of these patients had failed other forms of therapy including ES. All patients were treated within 10 days of their bleeding episode, although most were treated much sooner (about $20 \%$ of the original group were treated when they were actively bleeding). There were no restrictions on what type of liver disease the patient had or on how sick they were at the time of the bleed - patients only needed to be well enough to undergo endoscopy safely. Patients in the open study were discouraged from betablocker use with a high success rate.

Patients entered into the randomized trials were selected so that there would be less heterogeneity between the treatment groups. Only patients that the primary care physician and gastroenterology consultant felt had a reasonable chance of surviving the current hospitalization and lived sufficiently close for easy follow-up were entered. Also, these patients were ones who had never been treated before with either ES or shunt surgery. The use of 
propranolol or other beta-blockers was an exclusion from these randomized trials. Patients with any type of liver disease complicated by portal hypertension were included.

\section{RESULTS}

The initial open trial with EVL included 146 patients. Grade 3 to 4 varices were found in 138 patients at initial endoscopy. Thirty-three (23\%) were actively bleeding at initial treatment; this was controlled in 31 (94\%). During the study period 39 patients $(27 \%)$ died, $16(11 \%)$ in the first 30 days. Eighteen patients $(12 \%)$ died of liver failure, eight ( $5 \%$ ) from bleeding, nine $(16 \%)$ from unrelated causes and three $(2 \%)$ after undergoing surgical or radiographic procedures to control portal hypertension. Overall survival in these patients was $73 \%$. Seventeen patients $(12 \%)$ were lost to follow-up.

Varices were eradicated or reduced to grade 1 or lower in 99 of the 125 patients $(79 \%)$ who survived more than 30 days. Variceal eradication was achieved in two to 17 sessions (mean 5.5). Recurrent bleeding occurred in 65 of the total patient group (45\%). Of those who survived more than 30 days, $57(46 \%)$ had recurrent bleeding.

Only four nonbleeding complications occurred during the first threeyear period of EVL treatments. One patient developed severe dysphagia after EVL that lasted for about $36 \mathrm{~h}$ and required topical (oral) anesthetics and antispasmodics to control symptoms. One patient had a meat impaction removed endoscopically after several sessions, but no stricture could be identified. Two patients developed mild strictures that resolved after one dilation session with taper-tipped mercury-filled dilators.

There were no major differences in outcome between the patients with alcoholic liver disease and those with other causes of portal hypertension (chronic hepatitis, primary biliary cirthosis, sclerosing cholangitis, etc).

A multicentre randomized trial comparing EVL with ES ( $1 \%$ sodium tetradecyl sulphate) in the treatment of bleeding varices was conducted at Denver, Houston, Portland and Los An-

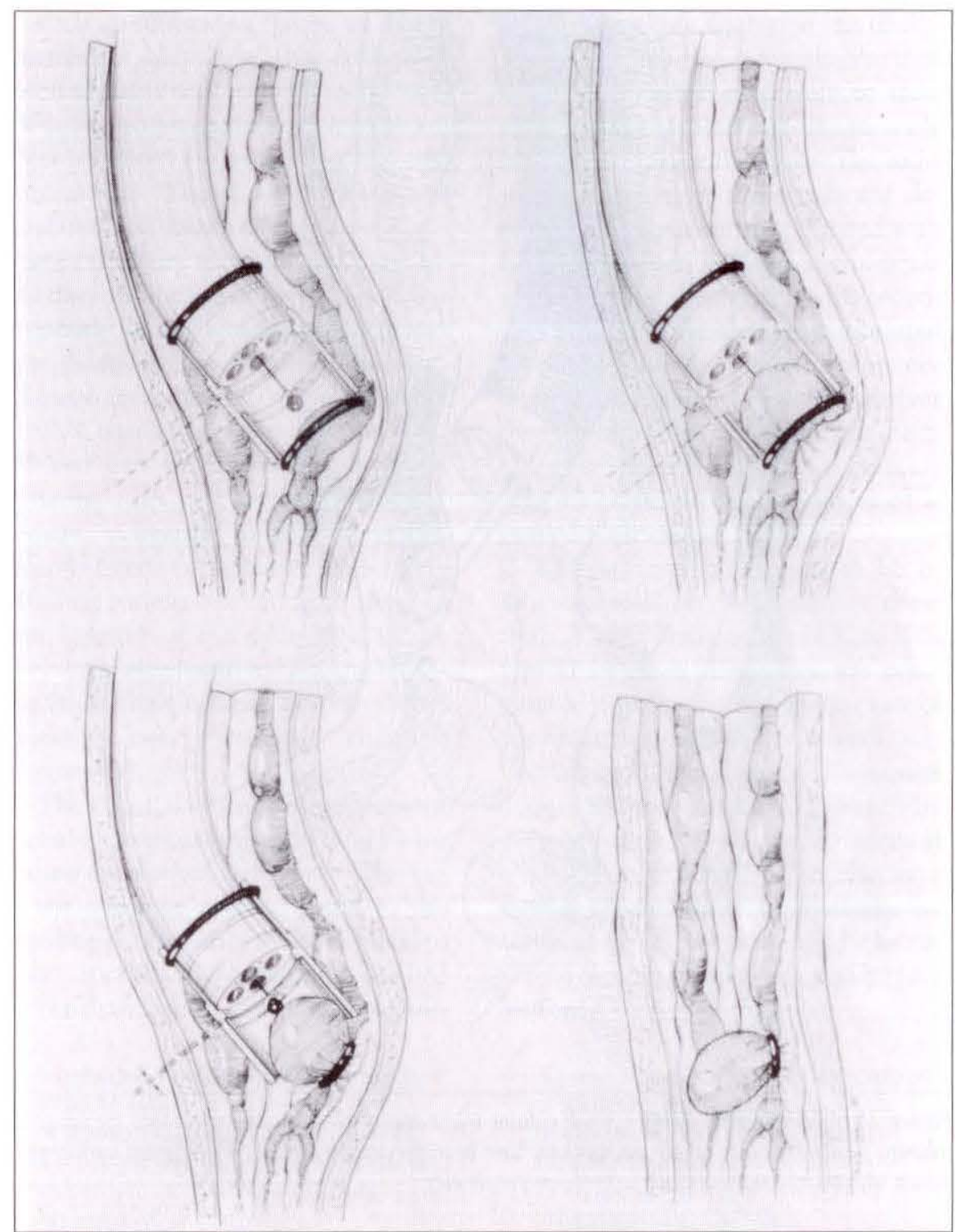

Figure 1) The endoscopic ligating device consists of an outer cylinder (composed of rigid and flexible portions) that slips over the tip of the endoscope, an inner cylinder over which the elastic o-ring is prefitted and a trip wire that attaches to the inner cylinder after being passed through the biopsy channel of the endoscope. The endoscope and device are passed into the distal esophagus and approximated to the mucosa overlying a varix (upper left). The tissue is aspirated into the dead space at the end of the endoscope (upper right). The trip wire is pulled, striping the o-ring (rubber band) off the inner cylinder and allowing it to close around the tissue containing the variceal channel (lower left). The final product is shown after removing the endoscope (lower right)

geles. There were 129 patients enrolled, half in each group. By Childs-Pugh classification approximately $50 \%$ of each group was class $\mathrm{B}, 30 \%$ was $\mathrm{A}$ and $20 \%$ was $\mathrm{C}$. The average transfusion requirement prior to treatment was three units. At their initial treatment endoscopy, $21 \%$ of patients were actively bleeding. Approximately $86 \%$ of patients entered had alcoholic liver disease. The average follow-up has been a little less than one year.
Of those actively bleeding at entry, $86 \%$ of the EVL group were controlled compared with $80 \%$ of the ES group. In the EVL group, 23 patients ( $36 \%$ ) had 33 rebleeding episodes. In the ES group, 31 patients $(48 \%)$ had 44 rebleeding episodes. There were no differences in the number of transfusions, hospital days or days from last treatment between the two groups. Three patients in the EVL group and eight in the ES group died of exsanguination. 


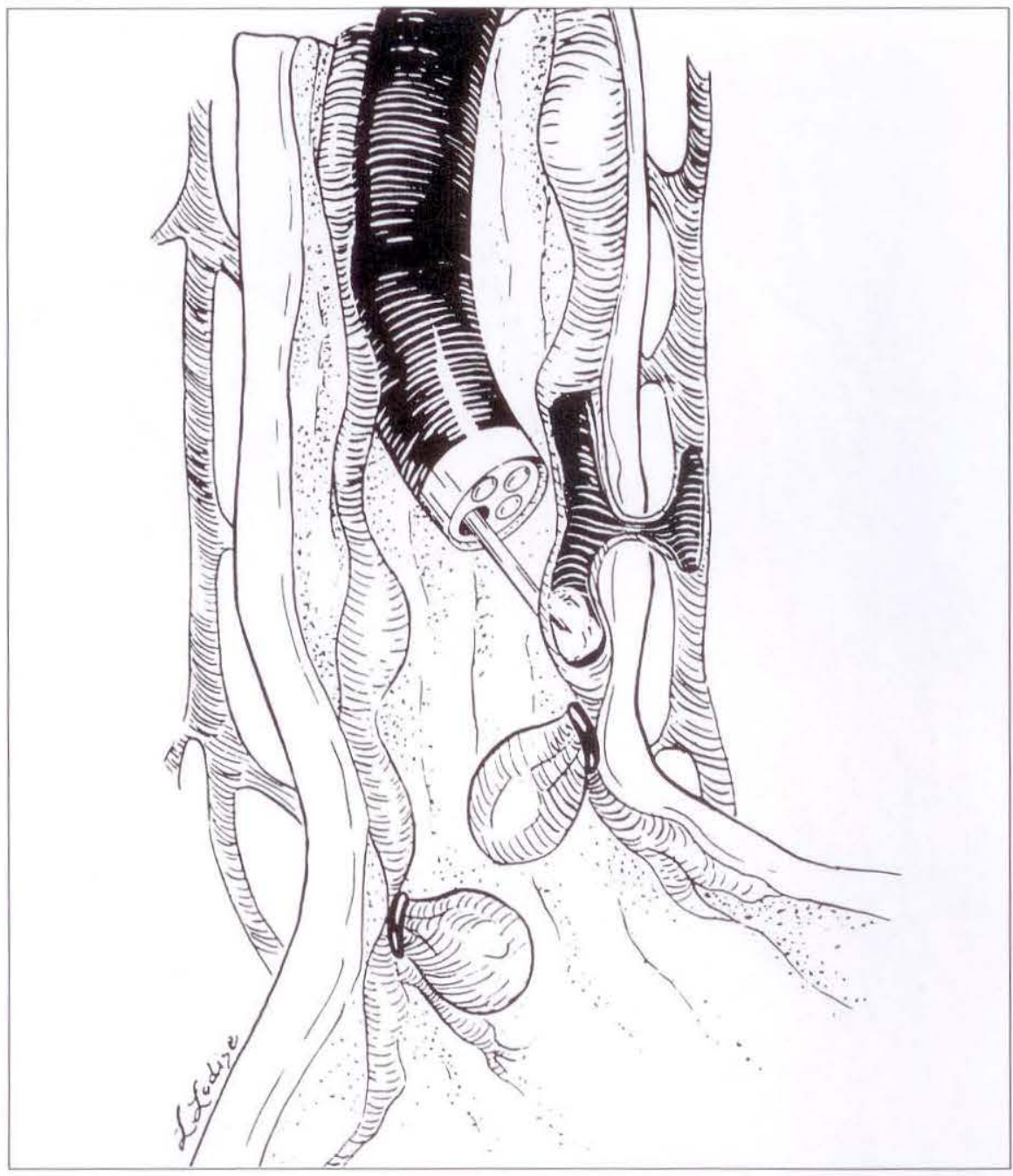

Figure 2) In combination therapy, small volume injections of sclerosant are made into the variceal columns just proximal to where the ligations have been previously applied. Two ligated varices are shown with an injection being performed just proximally

Total mortality was 28 and $45 \%$ in the EVL and ES groups, respectively, with the majority of deaths occurring in class C patients (75 and 92\%). Approximately $13 \%$ of each group required alternative therapy to control bleeding varices during the study. Recurrent varices were seen on follow-up endoscopy in $33 \%$ of EVL patients and $50 \%$ of ES patients.

Nonbleeding complications occurred in only one EVL patient $(2 \%)$ while 14 of the ES patients (22\%) had a variety of nonbleeding complications $(\mathrm{P}=0.001)$. The one EVL complication related to the procedure was pneumonia. Strictures requiring one to four dilations were seen in eight ES patients. Three ES patients had spontaneous bacterial peritonitis and four had pneu- monias and/or effusions. All complications except for one occurred in the class $\mathrm{A}$ and $\mathrm{B}$ patients.

A similar randomized trial comparing EVL and ES ( $1.5 \%$ sodium tetradecyl sulphate and $25 \%$ dextrose) was conducted at the University of Southern California in Los Angeles. All patients (20 EVL and $19 \mathrm{ES}$ ) bled at least two units before being eligible for the study. Over $90 \%$ of patients had alcoholic liver disease and most of them were Child's class B. None of the ES patients was class C. Treatment was performed once a week until the varices were eradicated.

At the initial endoscopy, 20\% of EVL patients and $32 \%$ of ES patients were actively bleeding (controlled in all but one patient in each group).
Rebleeding occurred in $25 \%$ of the EVL group and in $37 \%$ of the ES group. Eradication of esophageal varices took an average of 3.7 sessions for EVL and 5.8 sessions for ES. Deaths were equal in each group ( $5 \%$ ).

The overall nonbleeding complication rate was lower in the EVL group. Pneumonia and spontaneous bacterial peritonitis were seen in 10 and $15 \%$, respectively, of the EVL group, while each occurred at a $5 \%$ rate in the ES group. No strictures were noted in the EVL group, but $58 \%$ of the ES group developed them.

An open trial of a combination of EVL and ES ( $1 \%$ sodium tetradecyl sulphate) was conducted at the University of Colorado and the Denver Veterans Administration Medial Center. Fortysix cirrhotics with a mean age of 55 years were enrolled. Alcoholic liver disease made up $63 \%$ of the group, but only four patients had class $\mathrm{C}$ liver disease. The initial treatment session was followed by a second in one week and then every two weeks until eradication was achieved. The treating endoscopist had the option after the first session to use EVL alone, ES alone or a combination depending on the number and size of the patient's varices. The mean follow-up was approximately eight months.

Varices were reduced to grade 1 or lower in $76 \%$ of patients in an average of three sessions. Rebleeding occurred prior to eradication in 14 patients (30\%) and recurrent varices were seen in 10 patients $(21 \%)$. Death occurred in seven patients, but was due to exsanguination in only one. One patient developed an esophageal stricture. Combination therapy has also been used successfully to treat patients with bleeding fundic varices. A randomized multicentre trial now is underway to determine if these encouraging early results can be reproduced.

\section{DISCUSSION}

Sclerotherapy offers many advantages for the treatment of bleeding esophageal varices. It is quick and easy to employ, requires only moderate endoscopic skills, is minimally invasive and has been shown to control active 
bleeding and prevent recurrent hemorthage from varices (11). Unfortunately, there are several disadvantages to ES; it can be difficult to employ in patients who are actively bleeding at the time of ES, there are numerous complications some of which are life threatening), rebleeding occurs in up to $50 \%$ of patients especially during the interval before complete eradication is achieved and a survival advantage over conventional therapy has been difficult to demonstrate.

One of the problems with ES is the damage the sclerosant inflicts on the esophageal wall. The intent of ES is to damage the variceal channels and cause them to thrombose; however, it can be difficult to keep the sclerosant within the variceal channel and necrosis of the esophageal mucosa and the deeper layers may occur. It has been suggested that scarring and thickening of the esophageal mucosa and submucosa will reinforce the variceal channels and make them less prone to rupture (12). Controlling the amount of damage by attempts at changing the volume or type of sclerosant have met with only limited success.

\section{REFERENCES}

1. Ayres S, Goff J, Warren G. Endoscopic sclerotherapy for bleeding esophageal varices: Effects and complications. Ann Intern Med 1983;98:900-3.

2. Perino L, Gholson G, Goff J. Esophageal perforation after fiberoptic variceal sclerotherapy. J Clin Gastroenterol 1987;9:286-9.

3. Schuman B, Beckman ], Tedesco F, et al. Complications of endoscopic injection sclerotherapy: A review. Am J Gastroenterol 1987;82:823-9.

4. Sorensen T, Burcharth F, Pedersen M, et al. Oesophageal stricture and dysphagia after endoscopic sclerotherepy for bleeding varices. Gut 1984:25:473-8.

5. Stiegmann G, Sun J, Hammond W. Results of experimental endoscopic
EVL produces an ulcer at every treatment site since the entrapped piece of tissue wall necrose and slough off in two to seven days. The resulting ulcer is limited to the mucosa and submucosa (5). These superficial ulcers tend to heal faster since there is no chemical injury to tissue and they are less deep than ES-induced ulcers. Consequently, these ulcers produce fewer complications than the deep ES-induced esophageal ulcers.

EVL is much easier to perform than ES and can be readily employed in patients who are actively bleeding. Ideally, a ligation should be placed directly over a varix, but in the actively bleeding patient one can apply three or four ligations at the same level in the very distal esophagus to slow the bleeding (more ligations can be placed specifically over variceal channels proximally).

The initial ligation placement probably slows or stops bleeding by inducing esophageal wall spasm. The use of the overtube also is helpful to the bleeding patient since it allows blood to flow out of the esophagus onto the bed rather than into the patient's orophar-

esophageal variceal ligation. Am Surg 1988;54:105-8.

6. Stiegmann G, Goff J, Sun J, Davis D. Technique and early clinical results of erdoscopic variceal ligation. Surg Endosc 1989;3:73-8.

7. Reveille RM, Goff JS, Stiegmann GV, Stauffer JT. Combination endoscopic variceal ligation (EVL) and low. volume endoscopic sclerotherapy (ES) for bleeding esophageal varices: $\mathrm{A}$ faster route to variceal eradication? Gastrointest Endosc 1991;37:243.

8. Goff J, Reveille R, Stiegmann G. Endoscopic sclerotherapy versus endoscopic variceal ligation:

Esophageal symptoms, complications, and motility. Am ] Gastroenterol 1988;83:1240-4.

9. El-Newihi H, Migicovsky B, Laine L. ynx, thus making aspiration less likely.

Current studies have shown that EVL can be used effectively to treat patients with actively or recently bleeding esophageal varices. The most striking finding is the significant decrease in complications compared with ES. The author has had no patients with fevers or pleural effusions secondary to EVL. Chest pain has occurred briefly in a minority of patients immediately after EVL; it usually resolves over the next 12 to $24 \mathrm{~h}$. Simple strictures were observed in very few patients after EVL and no one had an esophageal perforation.

EVL appears to be equal to ES in efficacy based on the results of these trials. The rebleeding rates of 30 to $50 \%$ typical of most ES studies are comparable with the EVL rebleeding rate of approximately $45 \%$. An overall survival rate of approximately $75 \%$ is quite comparable to many ES studies. The average time to achieve variceal eradication ( 5.5 sessions) is also very similar to the three to five sessions reported for ES, but may even be better for the combination of EVL and ES (3.2 sessions).

A prospective, randomized comparison of sclerotherapy and ligation for the treatment of bleeding esophageal varices. Gastroenterology 1991;100:A59

10. Stiegmann GV, Goff JS, Michaletz-Onody PA, et al.

Endoscopic sclerotherapy as compared with endoscopic ligation for bleeding esophageal varices. N Engl J Med 1992;326:1527-32.

11. Health and Public Policy Committee. Endoscopic sclerotherapy for esophageal varices. Ann Int Med 1984:100:608-10.

12. Sarin SK, Nanda R, Sachdev G, et al. Intravariceal versus paravariceal sclerotherapy: A prospective, controlled, randomized trial. Gut 1987;28:657-62 


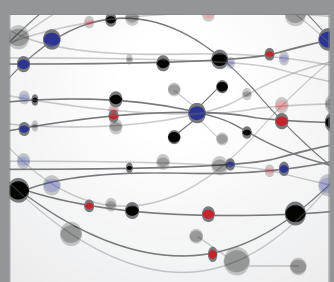

The Scientific World Journal
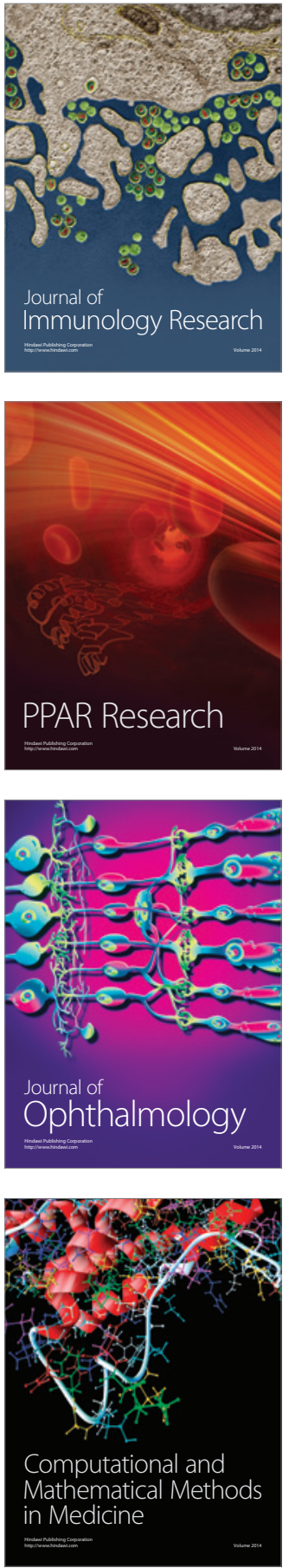

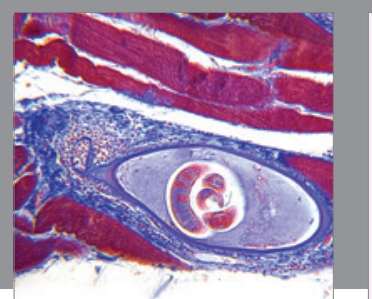

Gastroenterology Research and Practice

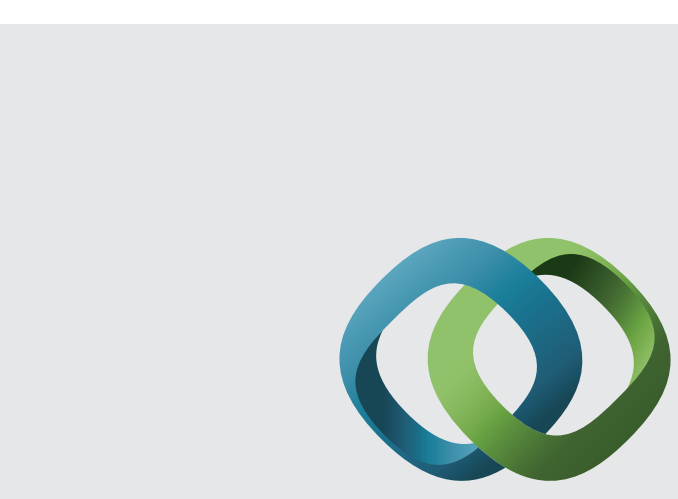

\section{Hindawi}

Submit your manuscripts at

http://www.hindawi.com
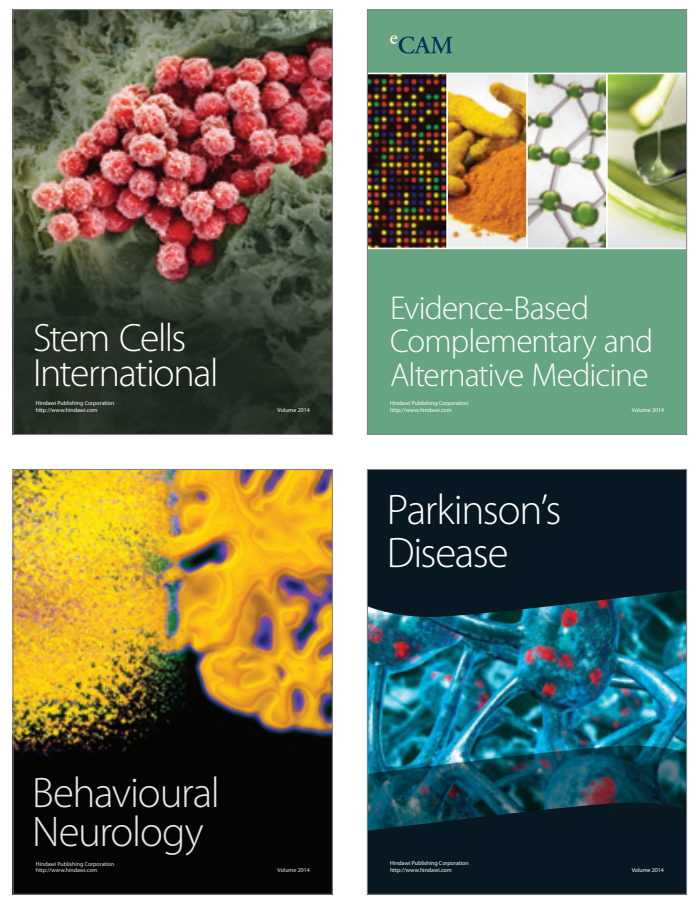
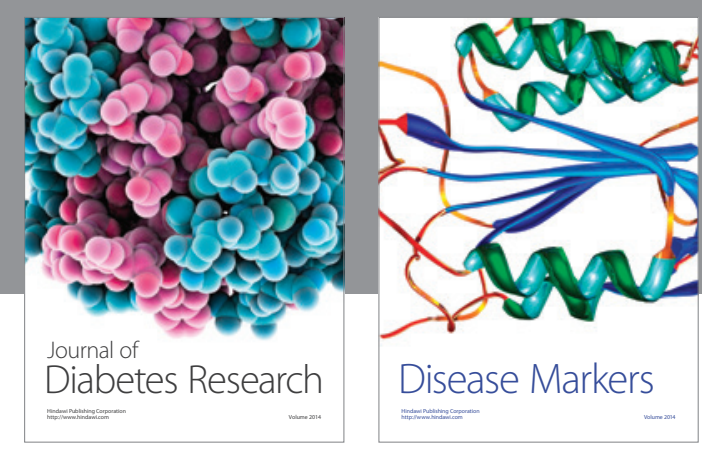

Disease Markers
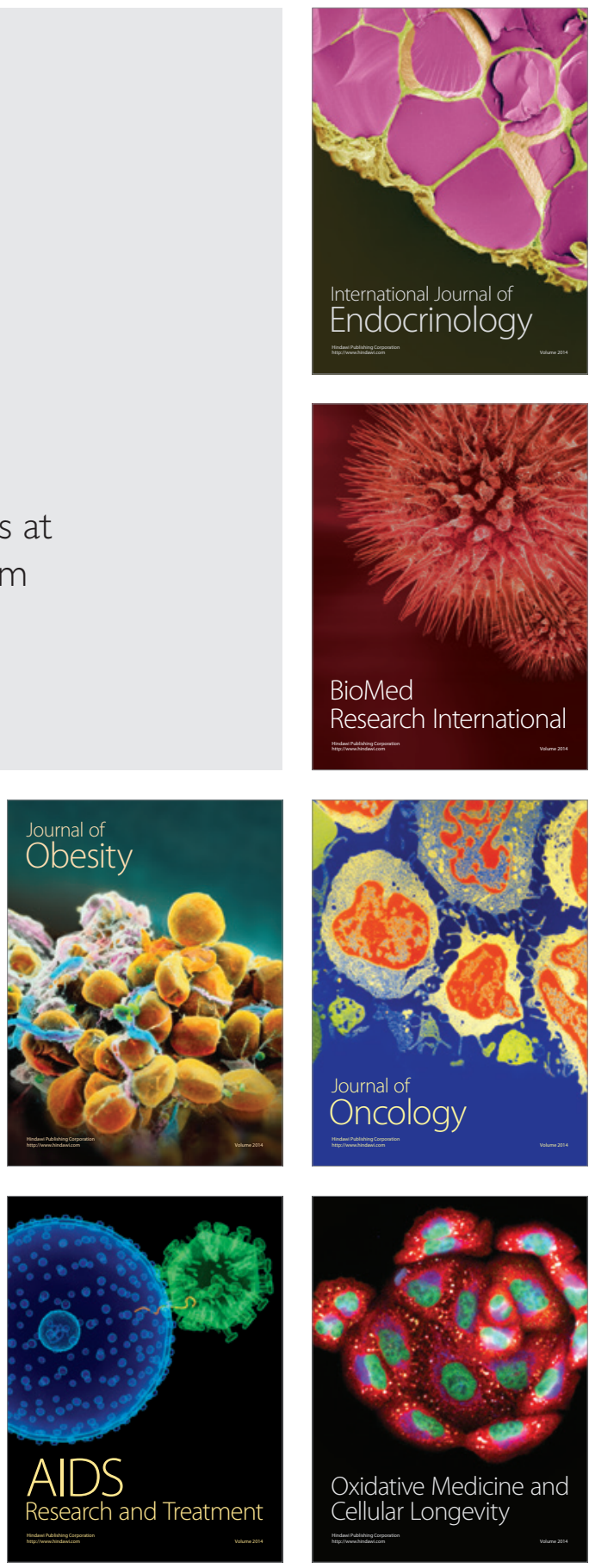